\title{
Delving into Personalisation Behaviours in a Language MOOC
}

\author{
Napat Jitpaisarnwattana \\ King Mongkut's University of Technology Thonburi, \\ Bangkok, Thailand \\ Pornapit Darasawang \\ King Mongkut's University of Technology Thonburi, \\ Bangkok, Thailand \\ Hayo Reinders \\ King Mongkut's University of Technology Thonburi, \\ Bangkok, Thailand
}

\begin{abstract}
Given the large amounts of learning data they generate and their flexible nature, Language Massive Open Online Courses (LMOOCs) allow for the emergence of various forms of personalisation. This study examines how 137 language learners personalised their learning in a Language MOOC on English presentation skills. It also investigates learner-reported reasons that encouraged them to either follow a personalised learning pathway (PLP) suggested to them by the system, or choose to devise their own individual (personal) learning plan (ILP). Data were collected using three instruments: course analytics, personalised questionnaires and semi-structured interviews. The results demonstrate that learners used several forms of personalisation, with an ILP being the most prominent. Learners who opted to follow a PLP cited an appropriate level of content as their primary reason for doing so, while those who chose to devise their own ILP cited having control over their learning and individual preferences as their main reasons. We conclude that LMOOC learners were more likely to devise their own learning plan than to follow a recommended plan and that the optimal design for an LMOOC is to combine both types of personalisation.
\end{abstract}

Keywords: Language MOOCs; Personalisation; Personalised learning; Personal Learning 


\section{Introduction}

In recent years, there has been a significant interest in Language Massive Open Online Courses (Language MOOCs or LMOOCs) as a result of the sudden shift to online learning globally. Due to their accessible and highly-structured nature, many language teachers have adopted LMOOCs as an alternative to or supplement to their regular teaching, resulting in increasing numbers of LMOOCs being offered worldwide (Author \& Author, 2021; Sallam, Martin-Monje and Li, 2020). Apart from these benefits, one potential of LMOOCs that has often been discussed is personalisation (Downes, 2013, 2016). This is because LMOOCs are highly heterogeneous, meaning that learners often differ in their backgrounds, learning needs, goals and preferences (Agonács \& Matos, 2019). Essentially, personalisation involves providing learners with choices in learning approaches, content and pace in order to cater to a wide range of individual learning differences. To this end, an adaptive learning or a recommendation system has been widely implemented. These systems provide learners with personalized feedback and content sequencing based on their profiles and performance on a given course (Godwin-Jones, 2014; Perifanou, 2015; Perifanou \& Economides, 2014)

In addition, as Moreira-Teixeira and Mota (2014) and Sokolik (2014) propose, learners should also be given the freedom to tailor how they want to participate in a given LMOOC. In other words, they should be allowed to personalise their own learning (personal learning) (Downes, 2013) and engage with their own personal learning environment (Godwin-Jones, 2009, 2017; Lantolf \& Thorne, 2006). These issues have, nonetheless, not yet been investigated empirically in the context of LMOOCs. Moreover, the reasons why learners choose to follow a recommended learning pathway or customise their own learning plan in the LMOOC environment remain unclear. The current study aims to fill this research gap by examining how learners in an LMOOC on English presentation skills made use of the personalisation opportunities offered to them. It also investigates the reasons behind their personalisation behaviours. Informed by data from course analytics, questionnaire responses and interview scripts, this study is guided by two research questions:

1. How did learners make use of the personalisation opportunities in the study's LMOOC?

2. What are the learners' reasons behind their personalisation behaviours in the LMOOC?

\section{Literature Review}

\subsection{Personalised and Personal Learning}

Personalised learning is considered to be one of the main pedagogical ideologies for the 21st century (Cavanagh, 2013). It offers choice in learning content, learning approaches and learning pace in order to meet individual learning differences. Learning a foreign language, in particular, is a complex process that involves a great deal of personal effort, interaction with authentic materials and contact with other learners. Importantly, language learners do not approach their learning in the same way. They often differ in their learning needs, learning goals, learning 
styles and preferences. Therefore, it is crucial for language teachers and course designers to address these individual differences.

Downes (2016) classified personalisation in education into two main types: personalised learning and personal learning. The main tenet of personalised learning is to use technology to make learning decisions for learners on a given course. Adaptive learning is a good example of this type of personalisation as it focuses on presenting learners with different course content based on a learner's prior experience or performance on learning tasks. In other words, learning is provided to learners via an adaptive or recommendation system. However, there is another kind of personalisation, personal learning (Downes, 2012, 2016). Personal learning supports making choices about learning rather than providing predetermined options to the learner. This means that learners are encouraged to create and interact with their own personal learning environments (PLEs). However, it is important to understand that personal learning is not only individual learning, it can also be facilitated through collaborative learning and social interaction. In our view, personalisation in the LMOOC context should include both types of personalisation. This means that learners should initially be provided with recommendations based on their learning profiles, but at the same time allowed and supported to tailor their own learning journeys and engage with and create their own PLEs.

\subsection{Personalisation and Language MOOCs}

With the advent of new developments in educational technology, efforts to improve personalisation have received increasing attention in the last decade. Sunar et al. (2016) conducted a review of the literature on personalisation in MOOCs and recognised three categories of research interest: a need for personalisation, proposals for personalisation and implementation of personalisation, the last of which is much less common. Pedagogically speaking, LMOOCs afford opportunities for increasing personalisation owing to their online infrastructure and adaptability to different pedagogical approaches. One example of this is the creation of a personal learning environment (PLE) (Perifanou, 2015; Perifanou \& Economides, 2014). Learners can be encouraged and supported to create their own learner-organised language learning environments. In these personal environments, learners can explore a wide range of digital tools and resources and use them to support different aspects of their learning, from goal-setting to materials selection and assessment (Author, 2014). Essentially, PLEs allow learners to be fully involved in the learning process by encouraging and guiding them to become co-creators of their knowledge (Attwell, 2007).

In addition, the tremendous amount of learning data that LMOOCs generate can be used to create learners' profiles (Author, Author \& Author, 2019). These profiles can be used to direct learners towards learning resources, tasks and activities that are suitable for their language ability (Bull \& Wasson, 2016). One clear example of this is the utilisation of a recommendation or adaptive system. When implemented, learners are presented with recommended learning materials or learning itineraries based on their background and performance. In language education, recommendation systems have been used to augment various 
language learning aspects, including reading ability (Hsu et al., 2013) and vocabulary (Nikiforov and Bledaite, 2012). Pedagogically speaking, the PLE concept has often been utilised under the connectivist MOOC (cMOOC) model (Downes, 2013, 2016) and a recommendation system, and adaptive learning has often been implemented in a more structured xMOOC model.

In the context of LMOOCs, only a few personalised learning systems have been implemented. One example of this was the use of Instreamia, an adaptive learning system to run MOOCs on several languages (Bárcena \& Martín-Monje, 2014; Godwin-Jones, 2014). Courses on the Instreamia platform provided personalised feedback and content sequencing to learners. In addition, the Open Learning Initiative (OLI), which makes use of cognitive and example-tracking-tutors, offers self-study learning resources in several languages. "Open learners' profiles", in which learners' interactions with the system are collected and used to develop a more effective adaptive learning system, have also been used (Godwin-Jones, 2014). Despite being a good starting point, these personalisation efforts have not yet been investigated empirically. On the basis of the above examples we can say that, despite initial efforts, it remains unclear to what extent personalisation can contribute to language learning in the LMOOC environment and to what extent learners make use of such personalised opportunities for their own learning. Also, factors that may influence learners' choices of following or not following personalised recommendations remain unclear. We argue that such choices need to be investigated from learners' viewpoints. The current study, therefore, aims to fill this gap in the body of literature on personalization in LMOOCs.

\section{Methods}

\subsection{The LMOOC}

Data were gathered from the Social and Personal Online Language Course (SPOLC), an LMOOC-type course that was designed to promote personalisation and interaction at a university in a large city in Thailand. The LMOOC was called Presentation @work. The content of the LMOOC covers essential aspects of delivering effective English presentations in professional and educational contexts. The course was delivered through Moodle, a learning management system platform. A personalised recommendation system was also integrated into the course. The system generates a personalised learning pathway (PLP) for each learner based on their profile and perceived ability (as measured through a selfevaluation questionnaire). The PLP suggests a learning sequence for learners to follow in order to improve their skills. However, they are told that they can customise the suggested pathway or even discard it completely and create their own individual learning plan (ILP) if they prefer. In addition, they can choose whether they want to work on their presentations individually or in small groups. Peer feedback and peer assessment were also incorporated as part of the course. The language of instruction was English and learners were only allowed to use English in the course. Despite being largely self-paced, the course was designed as a five-week course and the learners were informed of the expected course length at registration. 


\subsection{Participants}

There was a total of 270 learners who completed an initial self-evaluation questionnaire and received a personalised learning pathway (PLP). Personalised questionnaires based on their learning behaviours were sent to 270 learners after the course finished and 137 responses were received. Of these 137 learners, 54\% were working professionals from various occupations, including nurses, architects, engineers, medical scientists, teachers, and researchers, while $46 \%$ were still in formal education at either undergraduate $(21 \%)$ or graduate level $(25 \%)$. As for gender, $62 \%$ of the learners were females, while $32 \%$ were males. Six per cent of the learners chose not to associate themselves with any gender. Learners were broadly classified into four groups: 1) followed a PLP and created an ILP, 2) followed a PLP, but did not create an ILP, 3) did not follow a PLP, but created an ILP and 4) did neither. In addition, 22 learners agreed to do a semi-structured interview with one of the authors. These learners were invited based on their learning behaviours logged through learning analytics and their responses to the questionnaire.

\subsection{Data Collection - Instruments and Analysis}

This study adopted a mixed-methods approach to data collection and analysis. The data collection comprised three stages. In the first stage, learners' data on personalisation were logged through the analytics system of the course. The system records all learning activities that learners participated in. The data were mapped with the learners' PLPs for classification. In the second stage, we administered a personalisation questionnaire that was designed based on the learning behaviours of the participants. The questionnaire was administered one week after the course finished. Initially, there were four tentative versions of the personalisation questionnaire: 1) followed a PLP and created an ILP, 2) followed a PLP, but did not create an ILP, 3) did not follow a PLP, but created an ILP, 4) did neither (see Appendices 1, 2, 3 and 4). Each version of the questionnaire comprises two multiple response questions and six open-ended questions. The two multiple-response questions ask the participants to give reasons to explain their learning behaviours based on the four aforementioned categories. The six open-ended questions were designed based on three categories: interest, relevance to work/ study/ life and time spent in the LMOOC. The interest section of the questionnaire asks participants about the reasons why they chose to present on the topic that they chose or why they chose not to give a final presentation. The part about relevance to work/ study/ life asks the participants whether what they learned in the course was applicable to their lives. The last part asks the participants to justify the time they spent in the LMOOC. The questionnaire was personalised for every participant, meaning that each participant received a different version of the questionnaire based on their displayed learning behaviours. Personalisation of the questionnaires (Heerwegh et al., 2005) was carried out specifically for this study to gain more individualised data from the participants. To illustrate the process, all of the participants were classified into four personalisation behaviours. Then, data from each participant's learning logs, including completion / topic of the final presentation / time spent in the LMOOC, were incorporated to create a personalised questionnaire for every participant. This resulted in 270 versions of the personalisation questionnaire in this study. To confirm the content validity of the questionnaire, it was checked by three 
specialists in online language learning for item objective congruence (IOC). The analysis yielded a value of .971 , suggesting acceptable validity. The process of creating a personalised questionnaire is depicted in Figure 1, below:

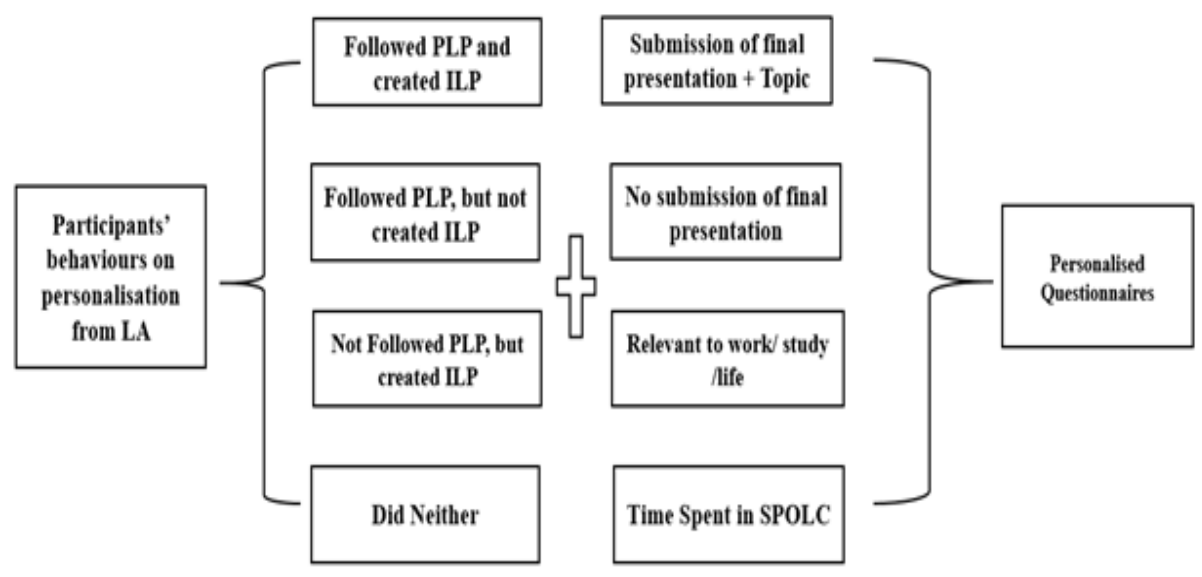

Figure 1: The process of creating a personalised questionnaire

The questionnaires (see Appendices 1, 2, 3, 4) were sent to all registered learners after the course ended and 137 responses were received. Responses to the questionnaire items were analysed using SPSS and descriptive statistics (multipleresponse analysis) were calculated. The open-ended questions were coded inductively using thematic content analysis. The coded scripts were used to support the responses to the personalisation questionnaire and to combine with data from the semi-structured interviews to create emerging themes.

In the final stage, all 137 participants who responded to the questionnaire were invited via email to conduct a semi-structured interview with the first author. The interviews, all conducted in Thai, were mainly conducted over Skype and Zoom and only two participants expressed a preference to do their interviews in person. The interviews were then transcribed and translated into English by one of the authors. To ensure the validity and accuracy of the translations, the translated scripts were presented to two university English lecturers for back translation. Finally, the transcripts, in both Thai and English, were offered to the interviewees for validation.

The interview transcripts were coded using thematic content analysis, following the procedure for qualitative analysis proposed by Saldaňa (2013). Adopting thematic content analysis (Saldaňa, 2013), the interview transcripts were coded deductively based on the items in the questionnaire, using the Nvivo 12 software package. Responses that did not correspond to the items in the questionnaire were coded inductively into emerging themes. To ensure the reliability of the coding process, the responses were coded by the researcher and $50 \%$ of the responses were sent to a university English lecturer for dual coding. Cohen's Kappa analysis was performed using SPSS. The analysis yielded a value of .956, indicating acceptable interrater reliability. 


\section{Results}

This section presents the analysis of the data on personalisation in this LMOOC, in two main parts according to the research questions: 1) How did learners make use of personalisation opportunities in the study's LMOOC? and 2) What are learners' reasons behind their personalisation behaviours in the LMOOC?

\subsection{How did learners make use of the personalisation opportunities in the study's LMOOC?}

In examining how the learners personalised their learning, descriptive statistical analysis was performed on the data logged in the course analytics. Table 1 indicates whether the learners followed the personalised learning pathway (PLP) recommended to them.

Table 1: Learners' use of their personalised learning pathway (PLP)

\begin{tabular}{lll}
\hline Number of learners & Followed PLP & Did not follow PLP \\
\hline 270 & $78(28.9 \%)$ & $192(71.1 \%)$ \\
\hline
\end{tabular}

Most of the learners (71.1\%) opted not to follow the PLP suggested to them, as only $28.9 \%$ did so. In addition to following the PLP, learners had a further option - whether or not to complete their own individual learning plan (ILP). The analysis of whether the learners devised an ILP is presented in Table 2, below:

Table 2: Learners' creation of an Individual Learning Plan (ILP)

\begin{tabular}{lll}
\hline Number of students & Created an ILP & Did not create an ILP \\
\hline 270 & $155(57.4 \%)$ & $115(42.6 \%)$ \\
\hline
\end{tabular}

Nearly 60 per cent of the learners created their own ILP for the course, while 42.6 per cent chose not to. Based on the above personalisation behaviours, the learners were categorised into four categories: followed a PLP and created an ILP, followed a PLP but did not create an ILP, did not follow a PLP but created an ILP and neither followed a PLP nor created an ILP, as shown in Table 3, below:

Table 3: Four groups of learners

\begin{tabular}{lllll}
\hline $\begin{array}{l}\text { Number of } \\
\text { students }\end{array}$ & $\begin{array}{l}\text { Followed a } \\
\text { PLP and } \\
\text { created an ILP }\end{array}$ & $\begin{array}{l}\text { Followed a PLP, } \\
\text { but did not } \\
\text { create an ILP }\end{array}$ & $\begin{array}{l}\text { Did not follow a } \\
\text { PLP but created } \\
\text { an ILP }\end{array}$ & $\begin{array}{l}\text { Neither followed } \\
\text { a PLP nor } \\
\text { created an ILP }\end{array}$ \\
\hline 270 & $68(25.2 \%)$ & $10(3.7 \%)$ & $87(32.2 \%)$ & $105(38.9 \%)$ \\
\hline
\end{tabular}

As can be seen, the largest percentage of the learners (38.9\%) opted not to follow the PLP recommended to them, nor did they devise their own ILP. A slightly smaller proportion of learners $(32.2 \%)$ chose not to follow their PLP, but did 
devise their own ILP, while only 3.7\% of the learners followed their PLP without creating an ILP. In addition, a quarter of the learners made use of both features. These results indicate that creating an ILP was a more popular personalisation feature than following a PLP. This also suggests that, when given choices, learners were more likely to engage with their own personal learning (ILP) rather than following recommended pathways (PLP). The next section probes the reasons behind the personalisation behaviours presented in this section.

\subsection{What are learners' reasons behind their personalisation behaviours in the LMOOC?}

The data analysed in this section come from two sources: responses to the personalisation questionnaire and interviews. The learners were asked in the personalisation questionnaire to specify the reasons behind their learning behaviours related to personalisation in the course. The results are presented based on four possible personalisation behaviours: 1) followed a PLP and created an ILP, 2) followed a PLP, but did not create an ILP, 3) did not follow a PLP, but created an ILP, 4) did neither.

\subsubsection{Group 1: Followed a PLP and created an ILP}

For the first group $(n=36)$, multiple response analysis illustrated that the right level of content was the most important reason for following a PLP, as cited by 20 learners $(55.6 \%)$, This was followed by interesting content, time efficiency of the plan, and suitability for their learning needs, each reported by 14 learners (38.9\%). The results of the analysis are shown in Table 4, below:

Table 4: Reasons for following a PLP by learners who followed a PLP and created an ILP

\begin{tabular}{lll}
\hline Reason & $\begin{array}{l}\text { Number of } \\
\text { responses } \\
\mathbf{( N = 3 6 )}\end{array}$ & $\begin{array}{l}\text { Percentage of } \\
\text { cases } \\
\mathbf{( N = 3 6 )}\end{array}$ \\
\hline $\begin{array}{l}\text { The personalised learning plan gave me the right } \\
\text { level of content that was suitable for my ability. }\end{array}$ & 20 & $55.6 \%$ \\
The plan gave me content I found interesting. & 14 & $38.9 \%$ \\
The plan was time-efficient to carry out. & 14 & $38.9 \%$ \\
The plan was suitable for my needs & 14 & $38.9 \%$ \\
\hline
\end{tabular}

The learners in this group were asked to identify their reasons for also creating their own ILP in addition to following a PLP. The analysis demonstrates that a majority of the participants $(61.1 \%)$ felt that devising their own learning plan would give them more control over their learning. Some learners, however, mentioned that they created their own plan because the PLP did not meet their learning needs, and so their own plan was more suitable, at $19.4 \%$ and $36.1 \%$, respectively. The analysis is shown in Table 5: 
Table 5: Reasons for creating an ILP by learners who followed a PLP and created an ILP

\begin{tabular}{lll}
\hline Reason & $\begin{array}{l}\text { Number of } \\
\text { responses } \\
(\mathbf{N}=36)\end{array}$ & $\begin{array}{l}\text { Percentage of } \\
\text { cases } \\
(\mathbf{N}=36)\end{array}$ \\
\hline It gave me more control over my learning. & 22 & $61.1 \%$ \\
$\begin{array}{l}\text { The plan offered to me did not meet my } \\
\text { needs. }\end{array}$ & 7 & $19.4 \%$ \\
$\begin{array}{l}\text { Creating my own plan was more suitable } \\
\text { for my needs. }\end{array}$ & 13 & $36.1 \%$ \\
\hline
\end{tabular}

Six out of the 22 learners who were interviewed belonged to this group. The qualitative analysis lends support to the multiple-response analysis shown above. Two learners confirmed that they followed a PLP because it was useful for them. For example, learner 33, when asked why she followed a PLP, stated:

"Yes, I did because I personally had problems with presentation, so the plan seemed useful for me." (Learner 33)

In addition, learner 19 mentioned that she originally followed a PLP, but later found that creating her own ILP could fit in better with her schedule:

"Initially, (I followed) the one provided, but as the course progressed, I felt that my own plan would fit better with my schedule, so I used my own plan more." (Learner 19)

It was interesting to discover that two participants found merit in combining a PLP with an ILP. They cited having both structure and freedom in their learning as their reason for combining the two options. For instance, learners 25 and 28 mentioned that:

"I think the pathway at the beginning was very useful because it pointed out areas where I needed to improve and I could improve based on that. Also, I could go beyond the plan and learn about what I wanted to know as well." (Learner25)

"I actually like both. Let me explain, there was a plan offered to me at the beginning of the course, this gave me a roadmap of what to do, but within that plan, I could still manage and use that plan in my own way." (Learner 28)

"Yes, partly, but it is also about the fact that we had a plan in the first place and we could tailor the plan to fit my needs. If there was no structure at all, people might not do it. If it was too strict, they might not do it either, so this was the right balance. People need different activities to sup-port their final presentation." (Learner 28)

As seen from the results above, it was possible for the learners in the LMOOC to make use of the personalised (PLP) and personal (ILP) features of the course as long as they saw that combining them was beneficial for their learning. 


\subsubsection{Group 2: Followed a PLP, but did not create an ILP}

Next is the second group of learners, who nly followed the PLP, but chose not to devise their own ILP ( $n=7)$. Multiple response analysis showed that interesting content and the suitability of the plan were the most important reasons for the learners to follow a PLP, each cited by five learners (71.4\%). This is followed by the efficiency of the plan and the right level of content, reported by four (57.1\%) and three $(42.9 \%)$ participants, respectively. The results of the analysis are illustrated in Table 6, below:

Table 6: Reasons for following a PLP by the learners who followed a PLP but chose not to create an ILP

\begin{tabular}{lll}
\hline Reason & $\begin{array}{l}\text { Number of } \\
\text { responses } \\
\mathbf{( N = 7 )}\end{array}$ & $\begin{array}{l}\text { Percentage of } \\
\text { cases } \\
\mathbf{( N = 7 )}\end{array}$ \\
\hline $\begin{array}{l}\text { A personalised learning plan gave me the right } \\
\text { level of content that was suitable for my ability. }\end{array}$ & 3 & $42.9 \%$ \\
$\begin{array}{l}\text { The plan gave me content I found interesting. } \\
\text { The plan was time-efficient to carry out. }\end{array}$ & 5 & $71.4 \%$ \\
The plan was suitable for my needs & 4 & $57.1 \%$ \\
\hline
\end{tabular}

This group of learners chose not to devise their own ILP. Almost all of the learners (85.7\%) felt that the PLP suggested to them was already suitable for their learning, hence no ILP was needed. It is interesting to note that two learners $(28.6 \%)$ did not believe that they could create their own plan. The analysis is shown in Table 7, below:

Table 7: Reasons for not creating an ILP by learners who followed a PLP but chose not to create an ILP

\begin{tabular}{lll}
\hline Reason & $\begin{array}{l}\text { Number of } \\
\text { responses } \\
(\mathbf{N}=7)\end{array}$ & $\begin{array}{l}\text { Percentage of } \\
\text { cases } \\
\mathbf{( N = 7 )}\end{array}$ \\
\hline $\begin{array}{l}\text { The plan suggested to me was already } \\
\text { suitable for my needs. }\end{array}$ & 6 & $85.7 \%$ \\
$\begin{array}{l}\text { It would take too long to create my own plan. } \\
\text { I cannot plan my own learning. }\end{array}$ & 0 & $0.0 \%$ \\
\hline
\end{tabular}

There was only one learner from this group who took part in an interview. The learner mentioned that he followed the plan because it was created based on his data, as learner 37 stated:

"Yes, I sort of did. Because the plan was generated based on my data. So, I looked at every activity that the plan suggested and tried to follow the plan, but I also looked at activities that were not in the plan as well." (Learner 37)

When asked why he chose not to create his own ILP, the learner mentioned that the pathway provided adequately responded to his needs

"I guess the suggested plan was already good for what I wanted to learn, so I did not feel that I had to create another plan on my own." (Learner 37) 


\subsubsection{Group 3: Did not follow a PLP but created an ILP}

Turning to the third group, these learners did not follow the PLP presented to them at the beginning of the course, instead devising their own learning ILP $(n=52)$. It can be seen from the results of the analysis that the learners saw the time-consuming nature of a PLP and changes in their learning needs as two main factors preventing them from following the plan, reported by $18(34.6 \%)$ and 17 $(32.7 \%)$ learners, respectively. Other reasons, including inappropriate level of suggested content, uninteresting content, a preference for vicarious learning, were cited by the same numbers of learners, at $23.1 \%$ each. The results are presented in Table 8, below:

Table 8: Reasons for not following a PLP by participants who did not follow a PLP but chose to create an ILP

\begin{tabular}{lll}
\hline Reason & $\begin{array}{l}\text { Number of } \\
\text { responses } \\
\mathbf{( N ~ = ~ 5 2 ) ~}\end{array}$ & $\begin{array}{l}\text { Percentage of } \\
\text { cases } \\
\mathbf{( N ~ = ~ 5 2 ) ~}\end{array}$ \\
\hline $\begin{array}{l}\text { A personalised learning plan did not give me the } \\
\text { right level of content that was suitable for my } \\
\text { ability. }\end{array}$ & 12 & $23.1 \%$ \\
$\begin{array}{l}\text { The plan did not give me content I found } \\
\text { interesting. }\end{array}$ & 12 & $23.1 \%$ \\
$\begin{array}{l}\text { The plan was taking too long to carry out. } \\
\text { Seeing other learners' videos gave me ideas for } \\
\text { how to better plan my own learning. }\end{array}$ & 18 & $34.6 \%$ \\
$\begin{array}{l}\text { My needs changed after I received the plan. } \\
\text { I think I can better plan my own learning. }\end{array}$ & 12 & $23.1 \%$ \\
\hline
\end{tabular}

This group of learners, nevertheless, opted to devise their own ILP. It can be clearly seen in the analysis that more than $75 \%$ of the learners created their own ILP because doing so gave them more control over their learning. While around a third of the learners felt that creating their own plan corresponded better to their needs, only a small number of participants felt that the PLP presented to them was inadequate $(9.6 \%)$. The results are shown in Table 9, below:

Table 9: Reasons for creating an ILP by participants who did not follow a PLP but chose to create an ILP

\begin{tabular}{lll}
\hline Reason & $\begin{array}{l}\text { Number of } \\
\text { responses } \\
\mathbf{( N ~ = ~ 5 2 ) ~}\end{array}$ & $\begin{array}{l}\text { Percentage of } \\
\text { cases } \\
\mathbf{( N ~ = 5 2 )}\end{array}$ \\
\hline It gave me more control over my learning. & 40 & $76.9 \%$ \\
$\begin{array}{l}\text { The plan suggested to me did not meet my } \\
\text { needs. }\end{array}$ & 5 & $9.6 \%$ \\
$\begin{array}{l}\text { Creating my own plan was more suitable } \\
\text { for my needs. }\end{array}$ & 16 & $30.8 \%$ \\
\hline
\end{tabular}


Eleven learners from this group took part in interviews. The analysis reinforces the notion that the suggested PLP was too time-consuming to follow. Two learners (learners 76 and 86) explicitly raised this issue in their interviews:

"No, I just had a look at it and ignored it. I think it was too timeconsuming to follow the plan." (Learner 76)

"Yes, I looked at the activities suggested in the pathway and followed it at first. But then I felt that those activities were too demanding for me to do as I was also very busy at work, so I did not finish every activity suggested." (Learner 86)

In terms of creating their own plan, the learners cited several reasons for devising their own ILP. First, as most of the learners also had other responsibilities, they felt that using their own plan was more practical for them, as learner 3 mentioned:

"Sometimes, I was busy with other responsibilities, so the fact that I could manage my own time helped me learn better in the course." (Learner 3)

Another learner added that people learn at different paces and using an ILP rather than the suggested PLP could accommodate such differences. On top of that, creating their own learning plan allowed the learners to be more motivated, less stressed and keep them on track with their learning. To illustrate, learners 76 and 136 said in their interviews:

"I think it motivated me to learn and explore what I really wanted to know. For example, if we choose the topic that we like, we can do it well. It was also easier for me to work on the topic I chose rather than an assigned topic." (Learner 76)

"I did because it was flexible and not forced. We could pick up some ideas from activities that were not recommended. Also, when we can design our own learning, it is more relaxing and less stressful." (Learner 136)

Interestingly, despite not following a PLP, the learners still found the suggested PLP useful, especially in terms of giving them a roadmap and structure that could be tailored to their preferences. This notion was mentioned by learners 21 and 44 in their interviews:

"I like the fact that it started from having a structure and gave me more freedom later, because I like to have a structure to start with so that I have a good basis and then I can just choose by myself." (Learner 21)

"I think there are two elements in this process. First, the provided plan gave me a roadmap of what I should do. It gave me a structure to follow and to stick with. It gave me a whole picture of what my learning would be about. Without that, my learning would be random. Then we could customise my plan based on that." (Learner 44)

\subsubsection{Group 4: Neither followed a PLP nor created an ILP}

The last group of learners in the analysis opted to neither follow a PLP nor create their own ILP $(n=42)$. The multiple-response analysis demonstrates that, echoing the results of the previous group, the time-consuming nature of the plan was the 
main reason preventing them from following the suggested plan $(35.7 \%)$, followed by an inappropriate level of suggested content and changes in their learning needs, at $31 \%$ and $28.36 \%$, respectively. The same number of learners $(n=$ 9) shared the notion that the content in the suggested plan was not interesting and they could devise a better learning plan, at $21.4 \%$. The results are shown in Table 10, below:

Table 10: Reasons for not following a PLP by participants who neither followed a PLP nor created an ILP

\begin{tabular}{lll}
\hline Reason & $\begin{array}{l}\text { Number of } \\
\text { responses } \\
\mathbf{( N = 4 2 )}\end{array}$ & $\begin{array}{l}\text { Percentage of } \\
\text { cases } \\
\mathbf{( N ~ = ~ 4 2 ) ~}\end{array}$ \\
\hline $\begin{array}{l}\text { The personalised learning plan did not give me } \\
\text { the right level of content that was suitable for my } \\
\text { ability. }\end{array}$ & 13 & $31 \%$ \\
$\begin{array}{l}\text { The plan did not give me content I found } \\
\text { interesting. }\end{array}$ & 9 & $21.4 \%$ \\
$\begin{array}{l}\text { The plan was taking too long to carry out. } \\
\begin{array}{l}\text { Seeing other learners gave me ideas for how to } \\
\text { better plan my own learning. }\end{array}\end{array}$ & 15 & $35.7 \%$ \\
$\begin{array}{l}\text { My needs changed after I received the plan. } \\
\text { I think I can better plan my own learning. }\end{array}$ & 12 & $19 \%$ \\
\hline
\end{tabular}

In addition to not following a PLP, this group of learners also did not devise their own learning plan. They saw the time required to create a plan as the main factor preventing them from doing so $(66.7 \%)$. While approximately a third of the learners were not confident in devising their own plan $(28.6 \%)$, a small number of them felt that the suggested plan was suitable for them. It is interesting to note here that despite viewing the suggested PLP as a suitable learning pathway, they did not follow it. The results of the analysis are presented in Table 11, below:

Table 11: Reasons for not creating an ILP by participants who neither followed a PLP nor created an ILP

\begin{tabular}{lll}
\hline Reason & $\begin{array}{l}\text { Number of } \\
\text { responses } \\
(\mathbf{N}=\mathbf{4 2})\end{array}$ & $\begin{array}{l}\text { Percentage of } \\
\text { cases } \\
\mathbf{( N ~ = 4 2 )}\end{array}$ \\
\hline $\begin{array}{l}\text { The plan suggested to me was already } \\
\text { suitable for my needs. }\end{array}$ & 9 & $21.4 \%$ \\
$\begin{array}{l}\text { It took too long to create my own plan. } \\
\text { I cannot plan my own learning. }\end{array}$ & 28 & $66.7 \%$ \\
\hline
\end{tabular}

Four learners from this group participated in interviews. Again, the learners emphasised that the suggested plan was too time-consuming to carry out. For instance, learner 134 mentioned:

"No, not really, the pathway suggested many activities to me, too many actually." (Learner 134) 
In terms of not creating an ILP, two learners stated explicitly in their interviews that it simply took too long to devise a plan of their own. When asked to provide reasons for not creating an ILP, Learners 117 and 134 replied:

"Because it was too time-consuming for me to create a plan. Also, I was not sure if I would follow the plan, so I decided not to." (Learner 117)

"I felt it took too much time to create a plan. I mean, after watching the introductory videos, I knew which activities I should do for my goal." (Learner 134)

Furthermore, though counterintuitive, the learners were asked to explain why they did not follow a PLP despite the fact they felt it was suitable for their learning. Learner 113 justified this in the interview thus:

"I was originally planning to follow the suggested plan, but as it was a very busy time of the year at work and I had to try to fit this MOOC into my schedule, sometimes, I even studied when I was working. It was just not possible to do what I intended." (Learner 113)

\section{Discussion}

This study has attempted to identify how learners make use of personalisation opportunities in an LMOOC. Two forms of personalisation were offered in the course: a personalised learning pathway (PLP) and an individual learning plan (ILP). The analysis shows that learners were far more likely to create their own individual learning plans (ILP) than to follow a personalised learning pathway (PLP) (through a recommendation system). Such a result might have been influenced by several factors, including individual preferences, expectations or even the practicality of following a suggested pathway. This is in line with Downes $(2013,2016)$, who argues that individual preferences might outweigh statistically-determined recommendations, such as those from a recommendation system. It also highlights the importance of personal learning in LMOOCs and emphasises the role personal learning environments have to play in facilitating language learning in the MOOC environment (Attwell, 2007; Reinders; 2014; Perifanou,2015; Perifanou \& Economides, 2014). However, it should be noted that, when looking at all possible types of personalisation, the largest proportion of learners $(38.9 \%)$ opted for neither option. This might be considered another form of personalisation in that participants exercised their choices beyond what was offered in the course. This also calls into question the quality of the recommended pathways and the practicality of the learners creating their own learning plan.

In terms of the reasons encouraging learners to follow a PLP, it was clear from the analysis that the learners cited an appropriate level of content as their primary reason. This is understandable, given that the PLPs were generated based on their self-evaluations. This confirms suggestions in the literature that learners' profiles can be used to direct learners towards appropriate learning materials and activities (Jitpaisarnwattana et al., 2019: Bull \& Wasson, 2016). However, many learners who opted not to follow a PLP felt that it was too time-consuming to adhere to and their needs changed as they progressed in the course. As a PLP factored in all information relating to English presentations from self-evaluation activity, it is possible that it suggested too many activities for the learners. Also, 
as most of the learners took the LMOOC in response to their needs at work or in their studies, which are generally quite dynamic and changing, it is probable that their needs would change after they started the course. These results suggest that there might be some discrepancies between the best learning scenarios the recommendation system aimed for and the practicality of following such recommendations, especially in terms of time requirements, as well as the dynamic nature of learning in an open learning space like an LMOOC.

Regarding ILPs, a majority of the learners felt that creating an ILP gave them more control over their learning. This is understandable given that ILPs were initially designed to allow participants to exercise more freedom in their learning. However, creating a learning plan was seen as too time-consuming by those learners who did not create an ILP. Some of them even expressed a lack of ability to plan their own learning. These results suggest that there might be variability in learners' propensity for autonomy in an LMOOC context. Learners in MOOCs might simply differ in terms of their awareness and ability to set learning goals and plan their own learning (Littlejohn et al., 2016; Milligan \& Littlejohn, 2016). In addition, it is interesting to note that some of the learners found merit in combining a PLP with their own ILP and that the PLP was perceived as a useful learning roadmap that could be tailored to their needs.

\section{Conclusion}

Learners in this study capitalised on the personalisation opportunities offered to them in various ways. The analysis of learners' personalisation behaviours shows that creating an individual learning plan (ILP) was the most popular personalisation feature among the learners, while a majority of them did not follow a suggested personalised learning plan (PLP). Also, it is interesting to see that the participants combined the suggested pathway with their own learning plan by using the PLP as a roadmap and an ILP as a customisation tool. In addition, learners reported several reasons behind their personalisation behaviours. The learners cited an appropriate level of the recommended content as their main reason for following their PLPs, whereas the time-consuming nature of the suggested pathway prevented them from doing so. For learners who opted to create an ILP, they attributed having more control over their learning as the factor encouraging them to create a plan, while the time required to devise a plan and the lack of ability to create one dissuaded them from doing so.

\section{Limitations and Further Research}

There are some limitations in this study that should be noted. First, this study is exploratory in nature and the findings come from only one LMOOC; therefore, findings might vary in other contexts. In addition, as all of the learners in this study were Thai, the findings may not be applicable to other LMOOCs with more diverse demographies. Future studies could examine the reasons behind personalisation behaviours from different LMOOCs to shed more light on personalisation in the LMOOC context. 


\section{Implications}

The results from this study have several implications for future LMOOC design and implementation. First, although the learners in this study did not make extensive use of PLPs, personalised learning and recommendations based on learners' profiles are still essential elements of the personalisation landscape in LMOOCs, as they can serve as a learning roadmap for learners. However, such a pathway should be positioned as a set of guidelines for learners to customise based on their interests and needs. Therefore, an optimal approach to personalisation in LMOOCs might be to combine personalised learning (Cavanaugh, 2013) with personal learning (Downes, 2016). Second, as the analysis indicates that it was not practical for many learners to follow their recommended PLPs, we do not suggest that the quality of recommendations should be compromised; rather, teachers may need to take more active and supportive roles to find ways to guide their learners to make the most of personalised path-ways in a practical manner.

\section{References}

Agonács, N., \& Matos, J. (2019). Understanding Language MOOC Learners: The Issue of Capability Development. International Journal of Emerging Technologies in Learning, 14(11), 1-15. https://doi.org/10.3991/ijet.v14i11.10205

Attwell, G. 2007. Personal learning environments - the future of eLearning? eLearning Papers, 2(1), 1-8.

https:// citeseerx.ist.psu.edu/viewdoc/download?doi=10.1.1.97.3011\&rep=rep1 \&type $=$ pdf

Barcena, E., \& Martin-Monje, E. (2014). Language MOOCs: An Emerging Field. In E. Martin-Monje \& E. Barcena (Eds.), Language MOOCs: Providing learning, transcending boundaries (pp. 1-10). De Gruyter Open. https:// doi.org/10.2478/9783110420067.1

Bull, S., \& Wasson B. (2016). Competence visualisation: Making sense of data from 21stcentury technologies in language learning. ReCALL, 28(2), 147-165. https://doi.org/10.1017/S0958344015000282

Cavanaugh, J. (2013). The Coming Personalization of Postsecondary Education Competencies. CAEL 2013 Forum \& News: Competency-Based Education pp. 25. https://cdn2.hubspot.net/hubfs/617695/premium_content_resources/CBEPublications/PDF/CAEL_competency_based_education_2013.pdf

Downes, S. (2012). Connectivism and Connective Knowledge. Retrieved from: http://www.downes.ca/files/books/Connective_Knowledge-19May2012.pdf

Downes, S. (2013). Evaluating a MOOC. Retrieved from: http://halfanhour.blogspot.co.uk/2013/03/evaluating-mooc.html

Downes, S. (2016). Personal and Personalized Learning. EMMA Newsletter, Online, European Multiple MOOCs Aggregator. Retrieved from: https:/ / www.downes.ca/cgi-bin/page.cgi?post $=65065$

Godwin-Jones, R. (2009). Personal learning environments. Language Learning $\mathcal{E}$ Technology, 13(2), 3-9. https:// www.lltjournal.org//item/2661

Godwin-Jones, R. (2014). Global reach and local practice: The promise of MOOCS. $\begin{array}{llll}\text { Language Learning } \& \text { Technology, 18(3), } & \text { 5-15. }\end{array}$ https://www.lltjournal.org/item/2863

Godwin-Jones, R. (2017). Scaling up and zooming in: Big data and personalization in language learning. Language Learning $\mathcal{E}$ Technology, 21(1), 4-15. https:// www.lltjournal.org/item/2979 
Heerwegh, D., Vanhove, T., Matthijs, K., \& Loosveldt, G. (2005). The effect of personalization on response rates and data quality in web surveys, International Journal of Social Research Methodology: Theory and Practice, 8, 85-99. https:// doi.org/10.1080/1364557042000203107

Hsu, C.-K., Hwang, G.-J., \& Chang, C.-K. (2013). A personalized recommendation-based mobile learning approach to improving the reading performance of EFL students. Computers \& Education, 63, 327-336. https://doi.org/10.1016/j.compedu.2012.12.004

Jitpaisarnwattana, N. \& Reinders, H. (2021). Language MOOCs. In: L. Liontas (Ed.), The TESOL encyclopaedia of English language teaching. (pp. 1-6). Wiley. https:// doi.org/10.1002/9781118784235.eelt0999

Jitpaisarnwattana, N., Reinders, H., \& Darasawang, P. (2019). Language MOOCS: An Expanding Field. Technology in Language Teaching \& Learning, 1(1), 21-32. https:// doi.org/10.29140/tltl.v1n1.142

Lantolf, J. P., \& Thorne, S. L. (2006). Sociocultural theory and the genesis of second language development. Oxford University Press.

Littlejohn, A., Hood, N., Milligan, C., \& Mustain, P. (2016). Learning in MOOCs: Motivations and self-regulated learning in MOOCs. The Internet and Higher Education, 29, 40-48. https://doi.org/10.1016/j.iheduc.2015.12.003

Milligan, C., \& Littlejohn, A. (2016). How health professionals regulate their learning in massive open online courses. The Internet and Higher Education, 31, 113-121. https://doi.org/10.1016/j.iheduc.2016.07.005

Moreira Teixeira, A., \& Mota, J. (2014). A proposal for the methodological design of collaborative language MOOCs. In E. Martin-Monje \& E. Bárcena (Eds.), Language MOOCs: providing learning, transcending boundaries (pp. 33-47). De Gruyter Open. https://doi.org/10.2478/9783110420067.3

Nikiforovs, P., \& Bledaite, L. (2012), Personalized sequential language vocabulary learning recommender system. Retrieved from: https://pdfs.semanticscholar.o/d901 /b5dcf47db028f1e56b60b931b72d8767cb6a.pdf

Perifanou, M. (2015). Research report on the current state of language learning MOOCs worldwide: exploration, classification and evaluation. LangMOOC project. Retrieved from: http://www.langmooc.com/?cat=7

Perifanou, M., \& Economides, A. (2014). MOOCS for foreign language learning: an effort to explore and evaluate the first practices. In Gómez Chova, L., López Martínez, A. \& Candel Torres, I. (Eds). Proceedings of the INTED2014 conference (pp. 35613570).

Reinders, H. (2014). Personal learning environments for supporting out-of-class language learning. ELT Forum, 52(4), 14-19.

Saldaňa, J. (2013). The Coding Manual for Qualitative Researchers (2nd ed.). SAGE.

Sallam, H., Martín-Monje, E., \& Yan, L. (2020). Research trends in language MOOC studies: a systematic review of the published literature (2012-2018), Computer $\begin{array}{llll}\text { Assisted } & \text { Language } & \text { Learning. } & 33\end{array}$ https://doi.org/10.1080/09588221.2020.1744668

Sokolik, M. (2014). What constitutes an effective language MOOC? In E. Martin-Monje \& E. Barcena (Eds.), Language MOOCs: Providing learning, transcending boundaries. (pp. 6-32). De Gruyter Open. https://doi.org/10.2478/9783110420067.2

Sunar, A. S., Abdullah, N. A., White, S., \& Davis, H. (2016) Personalisation in MOOCs: A critical literature review. In: Zvacek, S., Restivo, M., Uhomoibhi, J., Helfert, M. (Eds), Computer supported education, (pp. 152-168). https://link.springer.com/chapter/10.1007/978-3-319-29585-5_9 